Lepr Rev (2000) 71, 121

\title{
Questionnaire survey
}

In 1998 Dr Simon Cathcart of the Wellcome Trust attended the 15th International Leprosy Conference in Beijing to promote the Topics in International Health (TIH) Leprosy CDROM. Following its successful launch at this prestigious conference, the TIH Leprosy disk now has some 400 users worldwide. In 1999 the TIH series as a whole was awarded a commendation by the British Medical Association in their annual medical book competition (electronic media) and to date more than 5000 disks in the series are being used in 89 countries, with the numbers growing steadily each month.

This year, the Trust has collaborated with Netherlands Leprosy Relief (NLR) to produce two translations of the leprosy disk, one into Portuguese and the other into Bahasa Indonesia. NLR will distribute the translated disks directly to their networks of local healthcare workers. This is the first translation of any of the TIH disks into a foreign language and will serve to increase usability in three countries with the highest endemicity of leprosy worldwide: Brazil, Mozambique and Indonesia.

As part of their continued programme of evaluation and improvement of the TIH series the Wellcome Trust, in collaboration with Leprosy Review, now invites individuals who have used the Leprosy CD-ROM to submit their overall impressions of this training tool, e.g. design, functionality, ease of use, etc. In addition, we would like to find out how useful the tutorials and images are in enabling individuals to recognise when a person has leprosy.

A questionnaire survey can be accessed and submitted through the LEPRA website (http://www.lepra.org.uk) or by e-mail, fax or post (details below). All responses will be treated with the strictest confidence and data gathered from the forms will be anonymous. However, it would be helpful if you could tell us where you used the disk (country and type of institution) and at what level you normally work (student, primary health care, nurse, doctor etc.).

The questionnaire should not take you more than 10 minutes to complete and all individuals who submit a completed questionnaire (by whatever means) before 1st September 2000 will be entered into a prize draw. The first three names selected at random on 1 st September will receive a CD of their choice from any of the currently available TIH titles.

We look forward to reading your responses and wish you all the very best of luck in the prize draw. Thank you for your help and co-operation.

Contact details: The Departmental Administrator, Tropical Medicine Resource, The Wellcome Trust, 210 Euston Road, London NW1 2BE, UK. Fax: 44 (0)20 7611 8270; e-mail: tmr@wellcome.ac.uk

LEPRA web site address: http://www.lepra.org.uk

Details of the TIH series and how to order are available by contacting: CAB International, Wallingford, Oxon, OX10 8DE, UK. Phone: 44 (0)1491 832111; Fax: 44 (0)1491 829292; e-mail: publishing@cabi.org 